Gut, 1987, 28, 955-959

\title{
Involvement of alpha-1 and alpha-2 adrenoceptors in the postlaparotomy intestinal motor disturbances in the rat
}

\author{
A SAGRADA, M J FARGEAS, AND L BUENO \\ From the Department of Pharmacology, INRA, Toulouse, France
}

SUMmaRY The effects of phentolamine, yohimbine and prazosin on laparotomy induced intestinal motor disturbances were studied in anaesthetised fasted rats previously equipped with electrodes, chronically implanted on the duodenum and jejunum. During continuous recording of interdigestive myoelectric activity, laparotomy under thiopental anaesthesia (Nesdonal $40 \mathrm{mg} / \mathrm{kg} \mathrm{ip}$ ) induced a primary phase of total inhibition of spiking activity lasting $26 \cdot 1 \pm 1 \cdot 3$ min (mean $\pm \mathrm{SE}$ ) followed by a period of disorganised activity, the first propagated migrating myoelectric complex (MMC) occurring $71.4 \pm 7.9 \mathrm{~min}$ after laparotomy. Phentolamine $(3 \mathrm{mg} / \mathrm{kg})$, or yohimbine (1 $\mathrm{mg} / \mathrm{kg}$ ) given im before laparotomy decreased by 48 and $49 \%$, respectively, the duration of postsurgical inhibition, with a normal MMC pattern occurring immediately after. In contrast, there was only a shortening of the postlaparotomy initial inhibition of spiking activity after im prazosin $(100 \mu \mathrm{g} / \mathrm{kg})$, with a late $(50-60 \mathrm{~min})$ recovery of the MMC pattern. These results suggest that the initial inhibition of intestinal motility induced by laparotomy may involve alpha- 1 and alpha- 2 adrenoceptors, while the disruption of the MMC pattern is mainly caused by the activation of alpha-2 receptors.

A transitory suppression of gastrointestinal motility (ileus) is a common complication of abdominal surgery and trauma. Although stomach and colon are generally believed to be most affected, ' a period of postsurgical paresis of small bowel has been clearly shown in rats ${ }^{2}$ and dogs. ${ }^{3}$ In these species a clearcut suppression of spiking activity after laparotomy has been shown: the recovery of myoelectric activity occurs as incoordinated motility at first, followed by a progressive restoration of the organised fasted pattern - that is, the migrating myoelectric complex (MMC), which assumes the normal propulsive and secretory function. In both species, prolonged disruption of myoelectric activity caused by exposure of the bowel to air, intestine handling or related to the nature of surgery was observed. ${ }^{23}$ Moreover, the

Address for correspondence: Dr A Sagrada. Istituto De Angeli. Via Serio 15. 20139. Milano, Italy.

Received for publication 26 January 1987. propulsion of a marker along the small bowel of the rat is inhibited by laparotomy. ${ }^{\text {" }}$

In man, although postoperative radiological investigations attribute normal propulsive activity to small intestine, ' a disturbance in the coordination of myoelectric activity in the early postoperative period has been shown, with disruption of the basic electrical rhythm (slow waves) and irregular occurrence of spiking activity."

Hyperactivity of the sympathetic nervous system plays a prominent role in the genesis of this postsurgical event: ${ }^{7}$ it is prevented in rats by chemical and surgical sympathectomy, ${ }^{4}$ but not by adrenalectomy. Sympathetic hyperactivity also seems to be basic to gastric $^{x}$ and colonic ${ }^{4}$ ileus, if produced by peritoneal irritation, and to act synergistically with vagal nonadrenergic inhibitory fibres in decreasing gastric motility after laparotomy."' The roles of alpha-2 receptors located in the gut and involved in the 
regulation of gastrointestinal secretion and motility are widely documented ${ }^{11-1+}$ on the other hand, the role of alpha-1 receptors in this field is less clear. The present study was undertaken in order to clarify the role played by alpha- 1 and alpha- 2 receptors in the genesis of postsurgical ileus in the rat.

\section{Methods}

ANIMALS

Male Wistar rats, weighing 250-300 g were used; they were housed in individual cages, fed on UAR pellet diet and given water ad libitum. Under halothane (Fluothane) anaesthesia, Nichrome wire electrodes $(0.08 \mathrm{~mm}$ diameter) were implanted into the muscular layers of the small bowel, according to a previously described technique. ${ }^{15}$ The groups of electrodes were placed respectively on the duodenum at approximately $10 \mathrm{~cm}$ from the pylorus, and on the jejunum at approximately 20 and $30 \mathrm{~cm}$ from the pylorus.

\section{EXPERIMENTAL PROCEDURES}

Starting five to six days after surgery, the electrical activity of small bowel was recorded by means of an electroencephalograph (Reega Minihuit, Alvar; time constant $0 \cdot 1 \mathrm{sec}$; paper speed $6 \mathrm{~mm} / \mathrm{min}$ ). In addition an integrated record of spiking activity was obtained by summation of the electrical activity for consecutive 20 second periods using a linear integrator circuit ${ }^{16}$ connected to a potentiometric recorder $(\mathrm{JJ}$ Lloyd CR 503; paper speed $6 \mathrm{~cm} / \mathrm{h}$ ).

Experiments were carried out at three day intervals on each rat. The animals were fasted overnight and water was allowed ad libitum. After two hours of control recording of the interdigestive cyclic activity of small bowel, anaesthesia was induced by intraperitoneal injection of $40 \mathrm{mg} / \mathrm{kg}$ thiopental (Nesdonal). A $2 \mathrm{~cm}$ paramedian laparotomy was done in the umbilical region, according to the following time schedule: incision of the skin 10 minutes after barbiturate administration (stage 1); incision of muscle layers and peritoneum during the occurrence, at the upper jejunal site, of the third MMC after thiopental injection (stage 2), followed by immediate closing of the laparotomic wound. Drugs to be tested (or vehicles) were injected by intramuscular route during the occurrence, at the upper jejunal site, of the second MMC after thiopental administration that is, about 15-18 minutes before performing stage 2 of surgery.

The drugs were dissolved in $0.5 \mathrm{ml}$ vehicle and injected in the following doses: phentolamine $\mathrm{HCl}$ : $3 \mathrm{mg} / \mathrm{kg}$; yohimbine $\mathrm{HCl}: 1 \mathrm{mg} / \mathrm{kg}$; prazosin $\mathrm{HCl}$ : $100 \mu \mathrm{g} / \mathrm{kg}$ (the doses refer to the compounds as salts). Phentolamine was dissolved in distilled water, yohimbine and prazosin were dissolved in a $10 \%$ dimethylsulphoxide/water solution. Control animals received either $0.5 \mathrm{ml}$ of the dimethylsulphoxide/ water solution intramuscularly $(n=4)$ or $0.5 \mathrm{ml}$ of distilled water $(n=4)$. Because no significant difference between the two control groups was found for each of the parameters considered (ANOVA), one control group was made by pooling the data.

\section{ANALYSIS OF DATA}

The following variables were considered: (a) time of complete inhibition of myoelectric activity: from stage 2 of surgery to the appearance of the first spiking activity at one of the recording sites; (b) time of disruption of the MMC pattern: from stage 2 to the appearance of the first MMC propagated over at least two recording sites; (c) MMC period: time between the beginning of regular spiking activity of successive complexes at the upper jejunal site. For each rat, basal MMC period is the mean of three successive periods before thiopental administration. In order to compare presurgical and postsurgical mean MMC periods, the mean of the periods between thiopental injection and stage 2 and the mean of the first three periods after laparotomy were calculated for each experiment.

\section{STATISTICAL ANALYSIS}

Data were analysed using Student's $t$ test for paired (variable c) or unpaired data (variables a and b).

\section{Results}

The small bowel motor profile in fasted rats was characterised by the occurrence of migrating myoelectric complexes having a mean period, at the upper jejunal site, of $13.9 \pm 0.7 \mathrm{~min}(\mathrm{n}=8)$, and comprising two phases of irregular and regular spiking activity, as previously described. ${ }^{16}$ Thiopental did not modify the cyclic motor profile; however, it induced lengthening of the MMC period by $15 \pm 2 \%$ $(p<0.05)$, and, in some experiments, shortening of the phase of irregular spiking activity $(n=2)$. Finally, a transient inhibition or disruption of the organised myoelectric activity just after the injection, rapidly followed by recovery of the normal motility pattern, was sometimes observed $(n=6)$.

\section{EFFECT OF LAPAROTOMY}

Paramedian incision of the skin did not significantly alter regular development and migration of the ongoing myoelectric complex (Figs 1,2). In contrast, incision of muscle layers and peritoneum produced the instantaneous interruption of the ongoing complex (Figs 1,2) and the complete inhibition of any spiking activity for $26 \cdot 1 \pm 1 \cdot 3 \mathrm{~min}$. Recovery of an irregular spiking activity was then detectable at one 


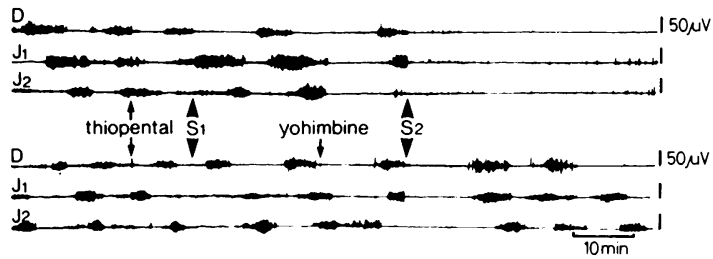

Fig. 1 Effect of laparotomy (S2) under thiopental anaesthesia on the myoelectric activity of duodenojejunum at $10(\mathrm{D}), 20(\mathrm{~J} 1)$ and $30(\mathrm{~J} 2) \mathrm{cm}$ from the pylorus (direct record). Upper traces: control laparotomy. Lower traces: laparotomy in yohimbine-treated rats $(1 \mathrm{mg} / \mathrm{kg} \mathrm{im}) . S 1$ indicates skin incision.

of the recording sites. The mean interval between stage 2 of the surgery and the reappearance of a myolectric complex propagated over at least two recording sites was longer, with a mean duration of $71.4 \pm 7.9 \mathrm{~min}$. At the recovery of the organised pattern, the MMC period was lengthened compared with the presurgical state $(\mathrm{p}<0 \cdot 01)$ (Table).

\section{EFFECT OF DRUGS}

\section{Phentolamine}

In animals pretreated with phentolamine, laparotomy immediately suppressed intestinal myoelectric activity; the duration of total inhibition of spiking activity was less compared with controls $(p<0 \cdot 01)$, as disorganised bursts of spikes reappeared 13.5 $\pm 0 \cdot 6$ min after laparotomy (Table). The MMC pattern recovered after $20.7 \pm 7.0 \mathrm{~min}(\mathrm{p}<0.05)$, but the MMC period was longer than presurgically $(\mathrm{p}<0.05)$ (Table).

\section{Yohimbine}

Pretreatment with yohimbine did not prevent the interruption of the MMC by laparotomy (Fig. 1); however, the suppression of myoelectric activity lasted $13 \cdot 2 \pm 1.9 \mathrm{~min}$, and the first MMC occurred $13 \cdot 6 \pm 2 \cdot 2$ min after stage 2 of surgery (Fig. 1,2). The recovery was faster than in controls $(p<0.01)$ and the MMC pattern was immediately organised; there was little or no effect of laparotomy on the MMC period $(p>0 \cdot 7)$ (Table).

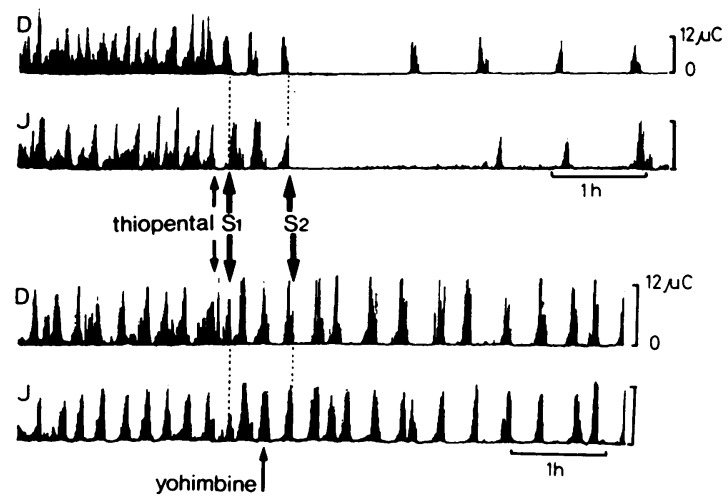

Fig. 2 Effect of laparotomy (S2) under thiopental anaesthesia on the myoelectric activity of duodenojejunum at $10(D)$ and $20(\mathrm{~J}) \mathrm{cm}$ from the pylorus (integrated record). Upper traces: control laparotomy. Lower traces: laparotomy in yohimbine treated rats $(1 \mathrm{mg} / \mathrm{kg} \mathrm{im})$. SI indicates skin incision.

\section{Prazosin}

Prazosin reduced the duration of laparotomy induced ileus $(\mathrm{p}<0.01)$, as with phentolamine or yohimbine; however, the reappearance of a propagated MMC was similar to controls ( $p>0.4)$, and the MMC profile showed a quite irregular frequency during several hours, with alternating periods of organised and disorganised spiking activity (Table).

\section{Discussion}

The present work confirms the inhibitory effect of laparotomy on the myoelectric activity of rat small bowel, ${ }^{2}$ and the participation of adrenergic pathways in the genesis of this pathology. ${ }^{247}$ Furthermore, it establishes that mainly alpha-2 adrenoceptors are involved. As previous works showed, thiopental anaesthesia leaves the interdigestive myoelectric pattern in rat substantially unchanged $;^{2}$ transient alterations sometimes observed in our experiments were probably caused by the stress of restraint and of the ip injection, and in these cases we waited

Table Influence of adrenoceptor blockers on the inhibition of duodenojejunal myoelectric activity induced by laparotomy in rats

\begin{tabular}{lllll}
\hline & & & \multicolumn{2}{c}{ Mean MMC period $($ min) } \\
\cline { 3 - 5 } & $\begin{array}{l}\text { Time }(\text { min) of myoelectric } \\
\text { activity inhibition }\end{array}$ & $\begin{array}{l}\text { Time }(\text { min) of MMC } \\
\text { pattern disruption }\end{array}$ & Presurgically & Postsurgically \\
\hline Controls $(\mathrm{n}=8)$ & $26 \cdot 1 \pm 1 \cdot 3$ & $71 \cdot 4 \pm 7 \cdot 9$ & $16 \cdot 4 \pm 1 \cdot 0$ & $30 \cdot 8 \pm 3 \cdot 8 \ddagger$ \\
Phentolamine $(\mathrm{im})(\mathrm{n}=4)$ & $13 \cdot 5 \pm 0 \cdot 6 \dagger$ & $20 \cdot 7 \pm 7 \cdot 0^{*}$ & $15 \cdot 5 \pm 1 \cdot 4$ & $21 \cdot 7 \pm 2 \cdot 3 \S$ \\
Yohimbinc $(\mathrm{im})(\mathrm{n}=5)$ & $13 \cdot 2 \pm 1 \cdot 9 \dagger$ & $13 \cdot 6 \pm 2 \cdot 2 \dagger$ & $17 \cdot 1 \pm 2 \cdot 4$ & $17 \cdot 5 \pm 3 \cdot 0$ \\
Prazosin $(\mathrm{im})(\mathrm{n}=5)$ & $13 \cdot 4 \pm 2 \cdot 2+$ & $52 \cdot 4 \pm 17 \cdot 0$ & $15 \cdot 2 \pm 1 \cdot 1$ & Not calculated \\
\hline
\end{tabular}

Values are means $\pm \mathrm{SE}$; difference $v$ controls: ${ }^{*}=\mathrm{p}<0 \cdot 05 ; \dagger=\mathrm{p}<0 \cdot 01$. Difference $v$ presurgical period: $\ddagger=\mathrm{p}<0 \cdot 05 ; \S=\mathrm{p}<0 \cdot 01$. 
for the recovery of the normal pattern before starting surgery. Incision of abdominal muscle layers and peritoneum abruptly interrupts intestinal motility, ? and this effect is consistently prevented by partial destruction of the spinal cord ${ }^{27}$ or by splanchnicectomy. ${ }^{2318}$ These data suggest the existence of an inhibitory reflex activated by laparotomy, involving the spinal cord and the splanchnic nerves as the main efferent pathway. In support of this proposition, increased synthesis and release of gut noradrenaline occurs 12 hours after abdominal surgery in rats. ${ }^{19}$ Moreover, adrenalectomy does not affect the postoperative slowing of rat small intestinal propulsion measured 12 hours after surgery. ${ }^{5}$

As previously shown, two phases occur in the postlaparotomy ileus: a total suppression of myoelectric activity, followed by a period of unorganised spiking activity. ${ }^{2}$ In our experiments the first period was shortened by phentolamine, yohimbine, or prazosin pretreatment, indicating that both alpha-1 and alpha-2 receptors may mediate inhibitory stimuli affecting small bowel motor activity postoperatively. The most important finding, however, concerns the faster recovery of the MMC pattern with phentolamine or, notably yohimbine. This early restoration of the MMC, not seen with prazosin, supports the hypothesis that alpha-2 receptors play a major role in the postlaparotomy disruption of the MMC pattern. Alpha-2 receptors can mediate inhibition of intestinal motility. ${ }^{12}=212$ Activation of these adrenoceptors, thought to be presynaptically located," can inhibit acetylcholine output in guinea pig ileum, ${ }^{2: 24}$ and a similar mechanism has also been proposed for dog jejunum ${ }^{21}$ and rabbit intestine. ${ }^{25}$ In rat small intestine, acetylcholine may not be the main excitatory neurotransmitter $; ;^{26}$ nevertheless, because clonidine $^{21}$ (and paradoxically prazosin ${ }^{27}$ reduces small bowel propulsive activity in rats, laparotomy induced ileus may be caused by the postoperatively increased release of gut noradrenaline, which, acting on presynaptic alpha-2 receptors, inhibits the release of a neurotransmitter important for the regularly cycling MMC. Alpha-2 receptors may also be important in regulating rat colonic motor activity, as inhibition of motility by nociceptive peritoneal stimuli was counteracted by phentolamine or yohimbine. ${ }^{9}$

Because there is a relationship between the MMC pattern and propulsion of contents in rat, ${ }^{152 x}$ peripheral blockade of alpha-2 adrenoceptors would be expected to result in a faster recovery of normal intestinal motility.

None of the drugs used prevented the instantaneous suppression of spiking activity caused by musculoperitoneal incision; other nervous pathways may therefore contribute to postlaparotomy ileus.

\section{References}

1 Rothnie NG, Kemp Harper RA, Catchpole BN. Early postoperative gastrointestinal motility. Lancet 1963; ii: 64-7.

2 Bueno L, Ferre JP, Ruckebusch Y. Effect of anesthesia and surgical procedures on intestinal myoclectric activity in rats. Am J Dig Dis 1978; 23: 690-5.

3 Bueno L, Fioramonti J, Ruckebusch Y. Postoperative intestinal motility in dogs and sheep. Am J Dig Dis 1978; 23: 682-9.

4 Dubois A, Weise VK, Kopin IJ. Postoperative ileus in the rat: physiopathology, etiology and treatment. Ann Surg 1973; 178: 781-6.

5 Dubois A, Henry DP, Kopin IJ. Plasma catecholamines and postoperative gastric and small intestinal propulsion in the rat. Gastroenterology $1975 ; 68$ : 466-9.

6 Dauchel J, Schang JC, Kacheloffer J, Eloy R, Grenier JF. Gastrointestinal myoelectric activity during the postoperative period in man. Digestion 1976; 14: 293-303.

7 Catchpole BN. Ileus: use of sympathetic blocking agents in its treatment. Surgery $1969 ;$ 66: 811-20.

8 Glise $H$, Lindhal BO, Abrahamsson $H$. Reflex adrenergic inhibition of gastric motility by nociceptive intestinal stimulation and peritoneal irritation in the cat. Scand J Gastroenterol 1980); 15: 773-82.

9 Sioqvist A, Hallerback B, Glise H. Reflex adrenergic inhibition of colonic motility in anesthetized rat caused by nociceptive stimuli of peritoneum. Dig Dis Sci 1985; 30: $749-54$.

10 Abrahamsson H, Glise H, Glise K. Reflex suppression of gastric motility during laparotomy and gastroduodenal nociceptive stimulation. Scand J Gastroenterol 1979; 14: 101-6.

11 Drew GM. Pharmacological characterization of the presynaptic alpha adrenoceptors regulating cholinergic activity in the guinea-pig ileum. Br J Pharmacol 1978; 64: $293-300$.

12 Doherty NS, Hancock AA. Role of alpha 2 adrenergic receptors in the control of diarrhea and intestinal motility. J Pharmacol Exp Ther 1983; 225: 269-74.

13 Nakaki T, Nakadate T, Yamamoto S, Kato R. Alpha 2 adrenergic inhibition of intestinal secretion induced by prostaglandin $E 1$, vasoactive intestinal polypeptide and dibutyryl cyclic AMP in rat jejunum. J Pharmacol Exp Ther 1982; 220: 637-41.

14 Cheng HC, Gleason EM, Nathan BA, Lachman PJ, Woodward JK. Effects of clonidine on gastric acid secretion in the rat. J Pharmacol Exp Ther 1981; 217: 121-6.

15 Ruckebusch M, Fioramonti J. Electrical spiking activity and propulsion in small intestine in fed and fasted rats. Gastroenterology 1975; 68: 1500-8.

16 Latour A. Un dispositif simple d'analyse quantitative de l'electromyogramme intestinal chronique. Ann Rech Vet 1973; 4: 347--53.

17 Alvarez WC. An introduction to gastroenterology. New York: Hoeber, 1948: 286-8.

18 Hukuhara T. Ein neues Verfahren der extraperitonealen Blosslegung der $\mathrm{Nn}$. splanchnici beim Kaninchen. Arch Ges Physiol 1936; 238: 135-6. 
19 Dubois A, Kopin IJ, Pettigrew KD, Jacobowitz DM. Chemical and histochemical studies of postoperative sympathetic activity in the digestive tract in rats. Gastroenterology 1974; 63: 403-7.

20 Nakahata N, Nakanishi H, Suzuki T. Prejunctional inhibition mediated via alpha 2 adrenoceptors in excitatory transmission of canine small intestine. J Pharm Pharmacol 1982; 34: 510-3.

21 Ruwart MJ, Klepper MS, Rush BD. Clonidine delays small intestinal transit in the rat. J Pharmacol Exp Ther 1980; 212: 487-90.

22 Wikberg JES, Lefkowitz RJ. Alpha 2 adrenergic receptors are located prejunctionally in the Auerbach's plexus of the guinea-pig small intestine: direct demonstration by radioligand binding. Life Sci 1982; 31: 2899-905.

23 Paton WDM, Vizi ES. The inhibitory action of noradrenaline and adrenaline on acetylcholine output by guinea-pig ileum longitudinal muscle strip. $\mathrm{Br} J$
Pharmacol 1969; 35: 10-28.

24 Kosterlitz HW, Lydon RJ, Watt AJ. The effects of adrenaline, noradrenaline and isoprenaline on inhibitory alpha and beta adrenoceptors in the longitudinal muscle of guinea-pig ileum. Br J Pharmacol 1970; 39: 398-413.

25 Vizi ES, Knoll J. The effects of sympathetic nerve stimulation and guanethidine on parasympathetic neuroeffector transmission; the inhibition of acetylcholine release. J Pharm Pharmacol 1971; 23: 91825.

26 Ruwart MJ, Klepper MS, Rush BD. Evidence for noncholinergic mediation of small intestinal transit in the rat. J Pharmacol Exp Ther 1979; 209: 462-5.

27 Rush BD, Ruwart MJ. Prazosin inhibits small intestinal transit in the rat. Br J Pharmacol 1984; 82: 547-8.

28 Wilen T, Gustavsson S, Jung B. Evidence for a propulsive function of the migrating myoelectric complex in rats. Eur Surg Res 1984; 16: 113-9. 